\title{
Effect of early prophylactic low-dose recombinant human erythropoietin on retinopathy of prematurity in very preterm infants
}

Huiqing Sun ${ }^{1 \dagger}$, Juan Song ${ }^{2 \dagger}$, Wenqing Kang ${ }^{1}$, Yong Wang ${ }^{2}$, Xiantao Sun ${ }^{3}$, Chongchen Zhou ${ }^{4}$, Hong Xiong ${ }^{1}$, Falin $\mathrm{Xu}^{2}$, Mingchao $\mathrm{Li}^{1}$, Xiaoli Zhang ${ }^{2}$, Zengyuan $\mathrm{Yu}^{1}$, Xirui Peng ${ }^{2}$, Bingbing Li ${ }^{2}$, Yiran $\mathrm{Xu}^{2}$, Shan Xing ${ }^{1}$, Xiaoyang Wang ${ }^{2,5}$ and Changlian $\mathrm{Zhu}^{2,6,7^{*}}$ (1)

\begin{abstract}
Background: Very preterm infants are at risk of developing retinopathy of prematurity (ROP). Recombinant human erythropoietin (rhEPO) is routinely used to prevent anemia in preterm infants; however, the effect of rhEPO on ROP development is still controversial. The purpose of this study was to evaluate the effect of early prophylactic low-dose rhEPO administration on ROP development in very preterm infants.

Methods: A total of 1898 preterm infants born before 32 weeks of gestation were included. Preterm infants received rhEPO ( $n=950 ; 500 \mathrm{U} / \mathrm{kg}$, rhEPO group) or saline ( $n=948$, control group) intravenously within $72 \mathrm{~h}$ of birth and then once every other day for 2 weeks.

Results: The total incidence of ROP was not significantly different between the two groups (10.2\% vs. 13.2\%, $p=0.055)$. Further analysis showed that rhEPO group had lower rates of type 2 ROP than the control group ( $2.2 \%$ vs. 4.1\%, RR 0.98; 95\% Cl 0.96-1.00; $p=0.021$ ). Subgroup analysis found that rhEPO treatment significantly decreased the incidence of type 2 ROP in infant boys ( $1.8 \%$ vs. $4.3 \%, p=0.021)$ and in those with a gestational age of $28-29^{6 / 7}$ weeks $(1.1 \%$ vs. $4.9 \%, p=0.002)$ and birth weight of $1000-1499 \mathrm{~g}(1.2 \%$ vs. $4.2 \%, p=0.002)$. There was a small increasing tendency for the incidence of ROP in infants with a gestational age of $<28$ weeks after rhEPO treatment.
\end{abstract}

Conclusions: Repeated low-dose rhEPO administration has no significant influence on the development of ROP; however, it may be effective for type 2 ROP in infant boys or in infants with gestational age $>28$ weeks and birth weight $>1500 \mathrm{~g}$.

Trial registration The data of this study were retrieved from two clinical studies registered ClinicalTrials.gov (NCT 02036073) on January 14, 2014, https://clinicaltrials.gov/ct2/show/NCT02036073; and (NCT03919500) on April 18, 2019. https://clinicaltrials.gov/ct2/show/NCT03919500.

Keywords: Erythropoietin, Retinopathy of prematurity, Preterm infant

\footnotetext{
${ }^{*}$ Correspondence: changlian.zhu@neuro.gu.se

${ }^{\dagger}$ Huiqing Sun and Juan Song contributed equally to this work

${ }^{6}$ Center for Brain Repair and Rehabilitation, Institute of Neuroscience and Physiology, University of Gothenburg, Gothenburg, Sweden Full list of author information is available at the end of the article
}

\section{Background}

Anaemia of prematurity is common in preterm infants, especially in very preterm infants born at $<32$ weeks of gestation [1]. It is caused by immaturity of the hematopoietic system, inadequate production of

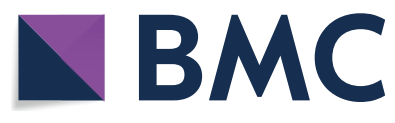

(c) The Author(s) 2020, corrected publication 2020. This article is licensed under a Creative Commons Attribution 4.0 International License, which permits use, sharing, adaptation, distribution and reproduction in any medium or format, as long as you give appropriate credit to the original author(s) and the source, provide a link to the Creative Commons licence, and indicate if changes were made. The images or other third party material in this article are included in the article's Creative Commons licence, unless indicated otherwise in a credit line to the material. If material is not included in the article's Creative Commons licence and your intended use is not permitted by statutory regulation or exceeds the permitted use, you will need to obtain permission directly from the copyright holder. To view a copy of this licence, visit http://creativecommons.org/licenses/by/4.0/. The Creative Commons Public Domain Dedication waiver (http://creativeco mmons.org/publicdomain/zero/1.0/) applies to the data made available in this article, unless otherwise stated in a credit line to the data. 
erythropoietin, and iatrogenic blood loss owing to frequent blood sampling [2]. Most very preterm infants receive blood transfusions for the treatment of anaemia during their hospitalisation [3], based on their haemoglobin levels, clinical indicators, and oxygen requirements [4]. Anaemia at birth has also been associated with the development of retinopathy of prematurity (ROP) [5], particularly in preterm infants with a gestational age of $<28$ weeks [6]. Moreover, the duration of anaemia during the first week of life is an independent risk factor for ROP, which may be reduced by treating and preventing early anaemia [7]. Previous studies have shown that the early administration of rhEPO is effective in preventing anaemia, thereby reducing the need for red blood cell transfusion in preterm infants $[6,8$, 9].

ROP is a proliferative retinal vascular disease affecting the retina of premature infants, and is characterised by neovascularisation, secondary to peripheral retinal ischemia, and subsequent neuro-vascular degeneration [10]. The clinical spectrum of ROP varies from spontaneous regression of the disease to bilateral retinal detachment, which can lead to total blindness [11]. Thus, to reduce the risk of blindness from retinal neovascularisation, retinal vasculopathy should be prevented. rhEPO is a powerful cytoprotective agent that protects both the neurons and vascular cells from apoptosis and mobilises bone marrow progenitor cells into the peripheral bloodstream for vascular repair $[12,13]$.

However, the effect of rhEPO administration on the development of ROP in preterm infants is still unclear. Vitreous levels of EPO are elevated in preterm infants who developed neovascularisation during phase 2 of ROP [14]. Moreover, serum EPO level was elevated 14 days after birth in preterm infants who developed severe ROP $[15,16]$, and was reduced 28 days after birth in preterm infants who developed any degree of ROP [17]. Consequently, it remains unclear whether rhEPO treatment is a risk factor for ROP development [1, 18-21]. Thus, we aimed to clarify the effect of rhEPO on ROP development in preterm infants by retrieving data from our previous prospective randomised rhEPO clinical trials in preterm infants (ClinicalTrials.gov: NCT02036073, NCT03919500). The purpose of these clinical trials was to test the hypothesis that early, repeated low-dose administration of rhEPO (500 $\mathrm{U} / \mathrm{kg}$ ) [9, 22], started within $72 \mathrm{~h}$ of birth and repeated once every other day for 2 weeks, was safe and would improve the neurological outcomes or reduce the incidence of necrotizing enterocolitis in very preterm infants. In the original clinical trials, ROP screening was routinely performed on premature and low birth weight infants with a gestational age $<32$ weeks or birth weight $<2000 \mathrm{~g}$ [23]; therefore, the data were available for all preterm infants enrolled in the clinical trials for retrieval of data and reanalysis.

\section{Methods \\ Subjects}

Data were retrieved from the original prospective randomised clinical trials performed at the neonatal intensive care units (NICUs) in Zhengzhou University, China. The eligible population for enrolment included infants admitted to the NICU at a gestational age of 24-32 weeks, within $72 \mathrm{~h}$ of birth. Infants with any of the following conditions were excluded from the study: genetic or metabolic diseases; major congenital abnormalities; a terminal stage of illness $(\mathrm{pH}<7.0$ or hypoxia with bradycardia $>2 \mathrm{~h}$ ); grade III/IV intracranial haemorrhage before randomisation; or lacking parental consent. A block randomisation method stratified by NICU size was used to assign infants 1:1 to either the control or rhEPO group in the previous clinical trials, and block randomisation also stratified by gestational age (<28 weeks, $28-29^{6 / 7}$ weeks, and 30-32 weeks) in NICUs [24]. The study was approved by the Life Science Ethics committee of Zhengzhou University and Henan Medical Academy in accordance with the Declaration of Helsinki.

The original design included several elements to ensure the safety of infants. All study procedures would cease if the infant suffered severe side effects. Criteria for withholding or stopping the study included major venous thrombosis; polycythaemia (haematocrit $>60 \%$ or haematocrit increase $\geq 15 \%$ not caused by transfusion); and hypertension (systemic blood pressure $>95 \mathrm{mmHg}$ at $0-7$ days of age, $>100 \mathrm{mmHg}$ at $8-14$ days, or $>105 \mathrm{mmHg}$ at $>14$ days) [9]. If the parents wished to withdraw consent at any time, all study procedures would cease.

\section{rhEPO administration}

Eligible infants received $500 \mathrm{U} / \mathrm{kg}$ rhEPO intravenously every other day for 2 weeks (a cumulative dose of 3500 $\mathrm{U} / \mathrm{kg}$ for seven separate intravenous injections, regardless of gestational age; this dose was safe and resulted in improved neurologic outcomes). The first dose was administered within $72 \mathrm{~h}$ of birth. Infants in the control group received an equivalent volume of saline, with the same treatment procedure as those in the rhEPO group. Supportive care, including temperature control, parenteral and enteral nutrition, and specific treatment of different clinical problems, were identical between the two treatment groups. Blood transfusion followed the strict clinical criteria [25]. 


\section{ROP screening and classification}

ROP screening was performed for all very preterm infants $\left(24^{0 / 7}-32\right)$ by qualified ophthalmologists with expertise, according to the Chinese guidelines for ROP screening [23]. Follow-up examinations were performed by the examining ophthalmologist based on retinal findings, classified according to the "International classification of retinopathy of prematurity revisited" [26, 27]. ROP was subdivided into stages $1-5$ according to the classification and defined as follows [27]: (1) none: immature or mature vascularisation; (2) ROP: stage 1 or stage 2 ROP in zone II or III without plus disease; (3) type 1 ROP: zone I, any stage ROP with plus disease; zone I, stage 3 ROP without plus disease; zone II, stage 2 or 3 ROP with plus disease; (4) type 2 ROP: zone I, stage 1 or 2 ROP without plus disease or zone II, stage 3 ROP without plus disease; and (5) ROP requiring treatment was defined as type 1 ROP or worse. Termination of ROP screening was performed before 45 weeks postmenstrual age (PMA) [26].

\section{Data collection and study outcomes}

Infant and maternal characteristics, delivery information, and outcomes data were collected using a data collection form and entered into a database for subsequent analysis. Study-specific variables, including weekly complete blood cell counts, and the number and volume of blood transfusions during hospitalization, were recorded. Routine blood tests were obtained before and after rhEPO treatment.

This study focused on short-term outcomes before the infant's 45 weeks of PMA, especially the incidence of ROP (all infants were survival at 45 weeks of PMA). The other short-term outcomes included the incidences of late-onset sepsis defined by a positive blood culture and treatment with antibiotics for $\geq 5$ days [28]; bronchopulmonary dysplasia (BPD) defined by persistent parenchymal lung disease, and radiographic confirmation of parenchymal lung disease at 36 weeks PMA in a premature infant [29]; necrotizing enterocolitis (NEC) $\geq$ stage 2 , according to the Bell's criteria [30]; severe intraventricular hemorrhage (IVH) $\geq$ grade 3 [31]; and duration of mechanical ventilation.

\section{Statistical analyses}

SPSS software version 21.0 (SPSS Chicago, Illinois, USA) was used for statistical analysis and data management. The outcomes, as well as infant and maternal characteristics, were summarised using descriptive methods and compared using the chi-square test for categorical variables and the $\mathrm{t}$-test for continuous variables. A multivariable logistic regression analysis model was used to adjust for potential confounding factors for type 1 or type 2 ROP. The model was adjusted for birth weight, NEC, and IVH. Interaction analysis in the subgroups was performed using the Mantel-Haenszel tests. The level of statistical significance was two-sided and defined by a p-value $<0.05$.

\section{Results \\ Baseline characteristics}

A total of 1898 very preterm infants were included (Fig. 1). The baseline characteristics of the infants in the rhEPO and control groups were similar in terms of birth weight and gestational age (Table 1).

\section{Effect of rhEPO on ROP}

Overall, there is a tendency of decreased incidence of ROP in the rhEPO group compared to that in the control group; however, the difference between the two groups was not statistically significant $(10.2 \%$ vs. $13.2 \%$, $\mathrm{p}=0.055$ ) (Table 2). The incidence of type 2 ROP was significantly lower in the rhEPO group than in the control group ( 2.2 vs. $4.1 \%, p=0.021)$. The incidence of combined type 1 or 2 ROP was $4.7 \%$ in the rhEPO group and $7.3 \%$ in the control group $(\mathrm{p}=0.022)$. However, there were no significant differences between the two groups regarding the incidence of type 1 ROP and mild ROP (Table 2). It is important to note that no type of ROP showed a significantly increased incidence in the rhEPO group when compared to the control group (Table 2). There were more infants who developed IVH and NEC in the control group than in the rhEPO group $(\mathrm{p}=0.001$ and $\mathrm{p}=0.012$, respectively), and also the mortality rate was higher in the control group $(\mathrm{p}=0.001)$. The rates of late onset sepsis, BPD, and duration of mechanical ventilation were similar between the two groups (Table 2).

\section{Subgroup analyses}

Subgroup analyses were performed based on gestational age ( $<28$ weeks, $28-29^{6 / 7}$ weeks, $30-32$ weeks) [24], birth weight $(<1000 \mathrm{~g}, 1000-1499 \mathrm{~g}, \geq 1500 \mathrm{~g})$, and sex. The incidence of type 1 ROP, type 2 ROP, and combined type 1 or type 2, was found to be associated with gestational age and birth weight $(\mathrm{p}<0.01$, respectively).

For type 1 ROP, no significant difference was observed in the sex, gestational age, and birth weight subgroup analyses. In infants with a birth weight of $<1,000 \mathrm{~g}$, there was a non-significant increase of type 1 ROP in the rhEPO group ( $15.9 \%$ vs. $9.6 \%, \mathrm{p}=0.409)$. However, there were no associations between rhEPO and sex, gestational age, or birth weight for type 1 ROP (Table 3).

For type 2 ROP, in infants with a gestational age of $<28$ weeks, the increasing tendency in ROP was observed $(12.5 \%$ vs. $6.0 \%, \mathrm{p}=0.342)$. The administration 


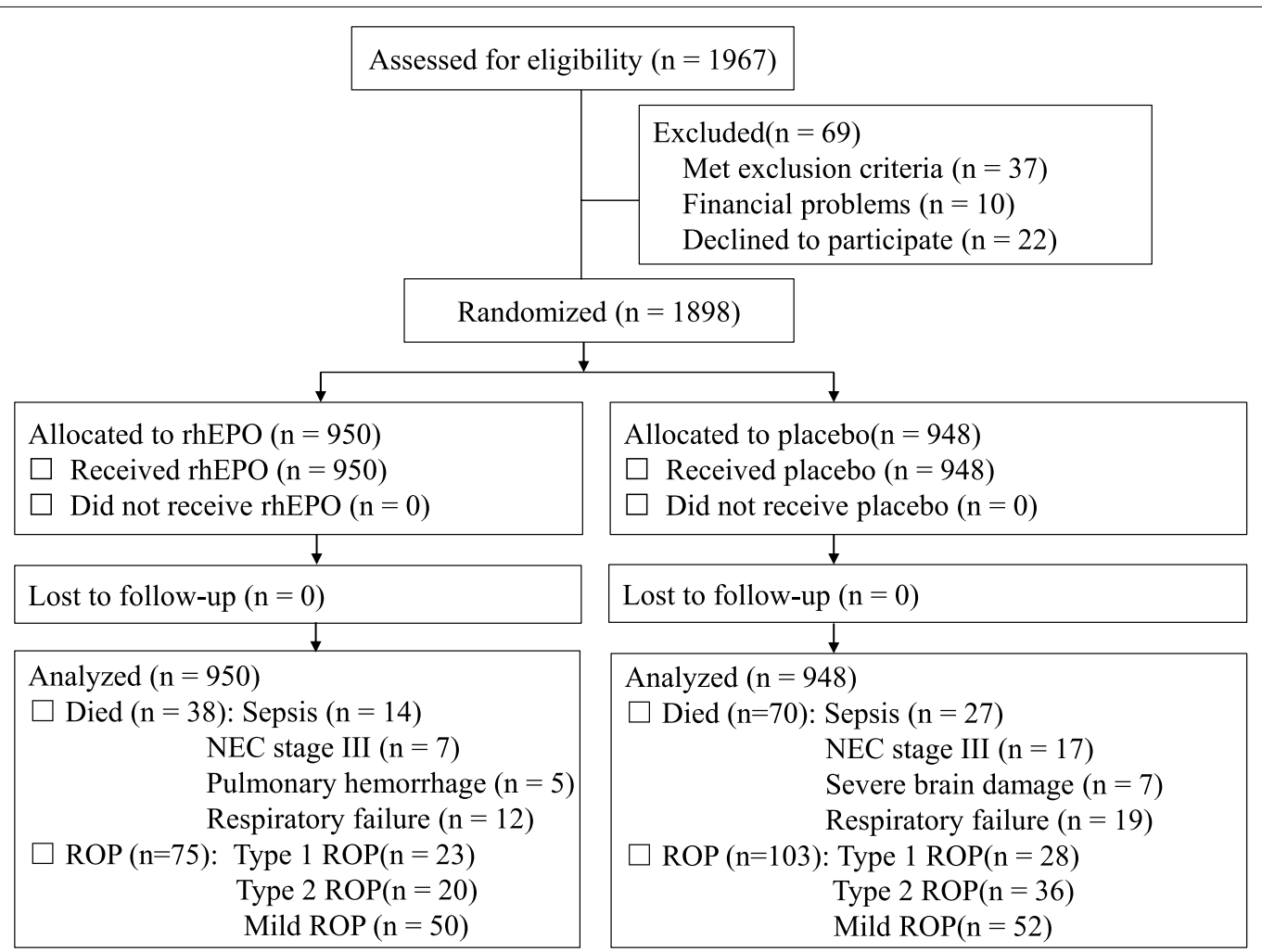

Fig. 1 Schematic flowchart shows the numbers of infants who were screened for eligibility, randomly assigned to the rhEPO or control group, and followed up to 45 weeks of corrected age. ROP, retinopathy of prematurity; NEC, necrotizing enterocolitis

Table 1 Baseline characteristics of all the infants enrolled in study

\begin{tabular}{|c|c|c|c|}
\hline Characteristic & Control $n=948$ & rhEPO $n=950$ & $P$ \\
\hline Male, n (\%) & $581(61.3)$ & $573(60.3)$ & 0.672 \\
\hline Gestational age (weeks), mean $\pm S D$ & $29.9 \pm 1.5$ & $29.8 \pm 1.8$ & 0.413 \\
\hline Birth weight (gram), mean $\pm S D$ & $1318 \pm 252$ & $1307 \pm 211$ & 0.298 \\
\hline Maternal age(years), mean $\pm S D$ & $29.6 \pm 5.4$ & $30.0 \pm 5.4$ & 0.124 \\
\hline Maternal hypertension, n (\%) & $199(21.0)$ & $185(19.5)$ & 0.424 \\
\hline Premature rupture of membrane, n (\%) & $255(26.9)$ & $257(27.1)$ & 0.959 \\
\hline Twins/multiple births, n (\%) & $137(14.5)$ & $110(11.6)$ & 0.066 \\
\hline Caesarean section, n (\%) & $403(42.5)$ & $382(40.2)$ & 0.328 \\
\hline Surfactant administration, n (\%) & $410(43.2)$ & $405(42.6)$ & 0.817 \\
\hline Clinical chorioamnionitis, n (\%) & $19(2.0)$ & $18(1.9)$ & 0.870 \\
\hline \multicolumn{4}{|l|}{ RDS } \\
\hline Grade 1, n (\%) & $367(38.7)$ & $356(37.5)$ & 0.603 \\
\hline Grade 2, n (\%) & $79(8.3)$ & $76(8.0)$ & 0.802 \\
\hline Grade $\geq 3, \mathrm{n}(\%)$ & $45(4.7))$ & $43(4.5)$ & 0.828 \\
\hline CPAP, n (\%) & $466(49.2)$ & $458(48.2)$ & 0.713 \\
\hline Requirement of oxygen, n (\%) & $804(84.8)$ & $780(82.1)$ & 0.122 \\
\hline Invasive mechanical ventilation, n (\%) & $327(34.5)$ & $291(30.6)$ & 0.078 \\
\hline Early-onset sepsis, n (\%) & $167(17.6)$ & $194(20.4)$ & 0.128 \\
\hline
\end{tabular}

$\mathrm{RDS}$, respiratory distress syndrome; CPAP, continuous positive airway pressure 
Table 2 Outcomes of ROP and other outcomes in two groups

\begin{tabular}{|c|c|c|c|c|}
\hline Outcomes & Control $n=948$ & rhEPO $n=950$ & $\mathrm{RR}(95 \% \mathrm{Cl})$ & $P$ value \\
\hline Death, n (\%) & $70 / 948(7.4)$ & $38 / 950(4.0)$ & $0.9(0.94-0.99)$ & 0.001 \\
\hline ROP, n (\%) & 116/878 (13.2) & 93/912 (10.2) & $0.97(0.93-1.00)$ & 0.055 \\
\hline Type 1 ROP, n (\%) & $28 / 878(3.2)$ & $23 / 912(2.5)$ & $0.99(0.98-1.01)$ & 0.478 \\
\hline Type 2 ROP, n (\%) & $36 / 878(4.1)$ & 20/912 (2.2) & $0.98(0.96-1.00)$ & 0.021 \\
\hline Type 1 or Type 2 ROP, n (\%) & $64 / 878(7.3)$ & $43 / 912(4.7)$ & $0.97(0.95-1.00)$ & 0.022 \\
\hline Mild ROP, n (\%) & $52 / 878(5.9)$ & $50 / 912(5.5)$ & $1.00(0.97-1.02)$ & 0.760 \\
\hline Hospital acquired sepsis, n (\%) & $255(26.9)$ & $232(24.4)$ & $0.97(0.92-1.0)$ & 0.227 \\
\hline BPD, n (\%) & $210(22.2)$ & $181(19.1)$ & $0.96(0.92-1.01)$ & 0.100 \\
\hline NEC, n (\%) & $51(5.4)$ & $29(3.1)$ & $0.98(0.96-1.00)$ & 0.012 \\
\hline IVH ( $\geq$ grade 3$), \mathrm{n}(\%)$ & $72(7.6)$ & $37(3.9)$ & $0.96(0.94-0.98)$ & 0.001 \\
\hline Mechanical ventilation, $d$ & $3.3 \pm 7.4$ & $2.9 \pm 5.5$ & $0.41(-0.39-1.23)$ & 0.313 \\
\hline
\end{tabular}

$\mathrm{Cl}$, confidence interval; rhEPO, recombinant human erythropoietin; ROP, retinopathy of prematurity. BPD, bronchopulmonary dysplasia; NEC, necrotizing enterocolitis; $\mathrm{IVH}$, intraventricular hemorrhage

of rhEPO actually led to a reduction in type 2 ROP incidence in infants with a gestational age of $28-29^{6 / 7}$ weeks (1.1\% vs. $4.9 \%, \mathrm{p}=0.002)$ and a birth weight of $1000-$ $1499 \mathrm{~g}(1.2 \%$ vs. $4.2 \%, \mathrm{p}=0.002)$, as well as in infant boys $(1.8 \%$ vs. $4.3 \%, \mathrm{p}=0.021)$ in comparison to that in the control group. Interaction analysis showed that sex, gestational age, or birth weight $(p=0.022, p=0.016$ and $\mathrm{p}=0.013$ respectively) may be the protective effect of rhEPO against type 2 ROP (Table 3 ).

For combined type 1 ROP or type 2 ROP, the administration of rhEPO significantly reduced the incidence of ROP (3.6\% vs. $7.8 \%, p=0.004)$ in infant boys, those with a gestational age of $30-32$ weeks $(2.9 \%$ vs. $6.2 \%, \mathrm{p}=0.014)$, and those with a birth weight $1,000-1,499 \mathrm{~g}(3.1 \%$ vs. $7.2 \%, \mathrm{p}=0.002)$. There were associations between rhEPO and sex, gestational age, or birth weight $(p=0.021$, $\mathrm{p}=0.012$ and $\mathrm{p}=0.008$ respectively) (Table 3 ), which means sex, gestational age, and birth weight could have an influence on the protective effect of rhEPO against combined type 1 ROP or type 2 ROP.

Multivariate logistic regression analysis revealed that the administration of rhEPO led to a decrease in the incidence of type $2 \mathrm{ROP}$, in comparison to the control group. The coefficient was -0.646 (odds ratio, $0.524 ; 95 \%$ CI 0.284 to 0.965 ) (Table 4). Except for rhEPO treatment, the birth weight was also associated with the development of ROP, and greater birth weight was, therefore, protective factors for type 2 ROP (Table 4).

\section{Safety analysis}

At the baseline, before the administration of rhEPO, complete blood counts of the infants in the rhEPO group and those of the infants in the control group were similar. On day 14, after the last dose of rhEPO was administered, red blood cell count, haemoglobin, and haematocrit in infants in the rhEPO group $[(3.3 \pm 0.5)$ $\times 10^{12} / \mathrm{L}, 106.3 \pm 23.6 \mathrm{~g} / \mathrm{L}$, and $32.2 \% \pm 7.1 \%$, respectively] were significantly higher than those of infants in the control group $\left[(3.0 \pm 0.5) \times 10^{12} / \mathrm{L}, 98.2 \pm 18.3 \mathrm{~g} / \mathrm{L}\right.$, and $29.8 \pm 5.5 \%$, all $\mathrm{p}<0.001$, respectively]. Accordingly, transfusion requirements were much lower in the rhEPO group (1.5 \pm 1.7$)$ than in the control group: $[1.8 \pm 1.9, \mathrm{RR}$ (95\% CI) 0.302 (0.181-0.424), $\mathrm{p}<0.001$ ] (Table 5).

Overall, rhEPO was well tolerated in the current treatment protocol. In very preterm infants, there were no differences between the rhEPO and control groups in liver and renal functions or in electrolyte levels (data not shown). In addition, no adverse effects, including allergic reactions, venous thromboses, rashes, or seizures, were observed in either the rhEPO or the control group.

\section{Discussion}

In these randomized trials reanalysis, we found that the effect of early administration of rhEPO on ROP in very preterm infants is associated with the gestation age, birth weight. Overall, low dose rhEPO treatment did not have an impact on the incidence of ROP development in very preterm infants. Rather, it was associated with a reduced risk of ROP in some groups of preterm infants. The incidence of type 2 ROP was reduced in infants with a gestational age between 28 and 30 weeks and bodyweight of 1000-1499 g compared to the control group. The administration of low dose rhEPO also reduced the incidence of type 2 ROP in infants with a gestational age between 28 and $29^{6 / 7}$ weeks and with a birth weight between 1000 and $1499 \mathrm{~g}$.

To note, in infants with a gestational age of $<28$ weeks and with a birth weight of $<1000 \mathrm{~g}$, there was a non-significant increased incidence of ROP. This may indicate that the effect of EPO on ROP in preterm infants might 


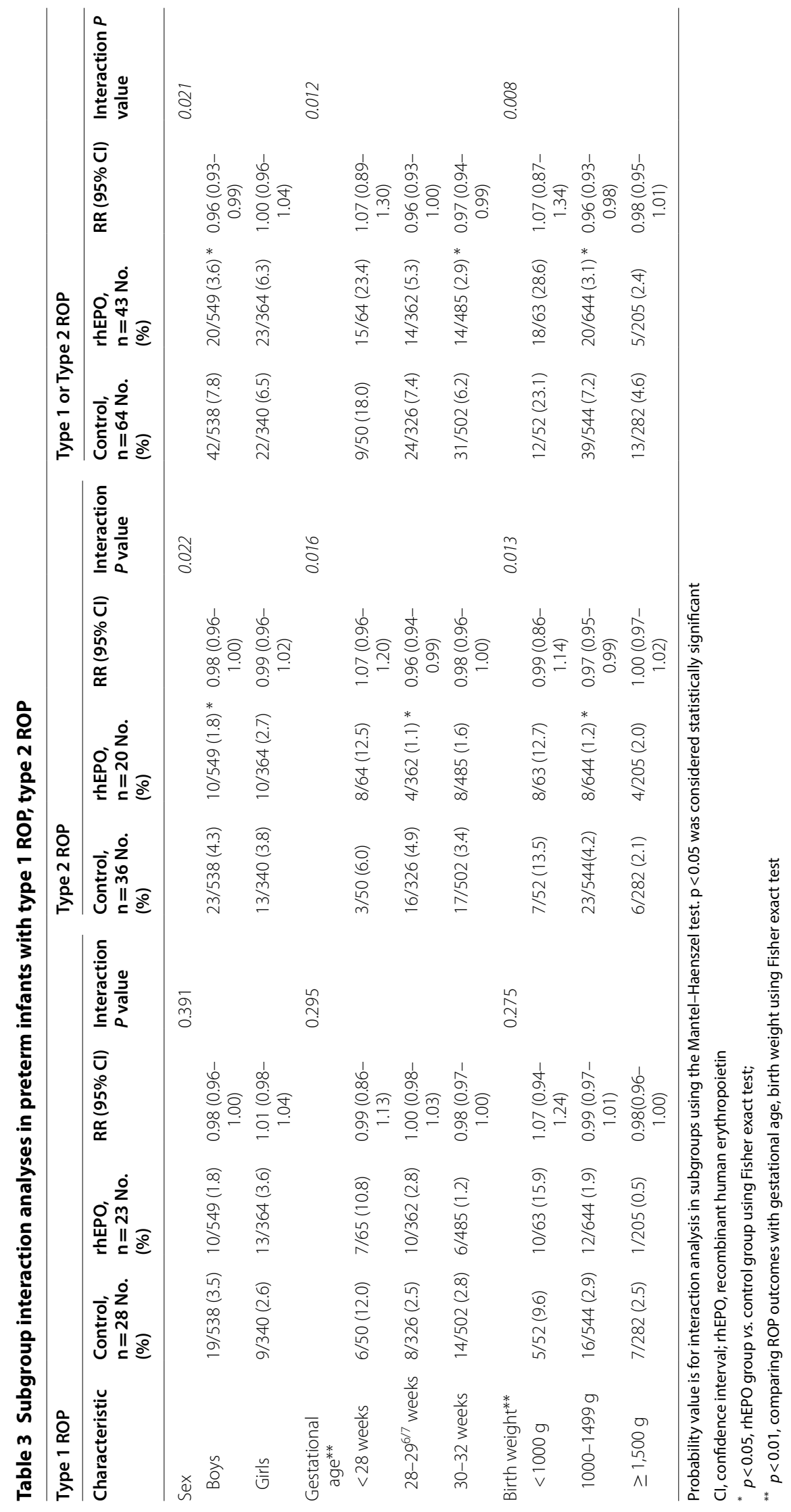


Table 4 Logistic regression analysis of risk factors for type 2 ROP

\begin{tabular}{lcccccr}
\hline & B & S.E. & Wald & df & Exp(B) (95\% Cl) & P value \\
\hline EPO & -0.646 & 0.313 & 4.264 & 1 & $-0.524(0.284-0.965)$ & 0.039 \\
Birth weight & -0.002 & 0.001 & 13.291 & 1 & $-0.998(0.997-0.999)$ & $<0.001$ \\
NEC & -0.130 & 0.631 & 0.042 & 1 & $-0.878(0.258-3.02)$ & 0.837 \\
IVH & 0.047 & 0.557 & 0.007 & 1 & $1.048(0.352-3.121)$ & 0.933 \\
Constant & 0.095 & 0.773 & 0.015 & 1 & 1.100 & 0.902 \\
\hline
\end{tabular}

$\mathrm{Cl}$, confidence interval; SE, standard error; Wald, Wald test. rhEPO, recombinant human erythropoietin; NEC, necrotizing enterocolitis; IVH, intraventricular hemorrhage

Table 5 Blood analysis before and after rhEPO administration

\begin{tabular}{|c|c|c|c|c|}
\hline & Control $n=948$ & rhEPO $n=950$ & Difference $(95 \% \mathrm{Cl})$ & $P$ value \\
\hline \multicolumn{5}{|c|}{ Before rhEPO administration } \\
\hline $\operatorname{RBC}$ count $\left(\times 10^{12} / \mathrm{L}\right)$ & $4.0 \pm 0.8$ & $3.9 \pm 0.6$ & $0.06(0.00-0.12)$ & 0.065 \\
\hline Hemoglobin $(g / l)$ & $139.5 \pm 29.1$ & $140.8 \pm 27.6$ & $1.30(-1.25-3.85)$ & 0.318 \\
\hline Hematocrit (\%), & $42.3 \pm 8.8$ & $42.7 \pm 8.4$ & $0.40(-0.37-1.17)$ & 0.311 \\
\hline Platelet $\left(10^{9} / \mathrm{L}\right.$ & $239.1 \pm 114.2$ & $246.1 \pm 108.4$ & $7.00(-3.02-17.02)$ & 0.171 \\
\hline \multicolumn{5}{|c|}{ After rhEPO administration } \\
\hline RBC count $\left(10^{12} / \mathrm{L}\right)$ & $3.0 \pm 0.5$ & $3.3 \pm 0.5$ & $0.30(0.25-0.35)$ & $<0.001$ \\
\hline Hemoglobin (g/l), & $98.2 \pm 18.3$ & $106.3 \pm 23.6$ & $8.10(6.20-10.00)$ & $<0.001$ \\
\hline Hematocrit (\%) & $29.8 \pm 5.5$ & $32.2 \pm 7.1$ & $2.40(1.83-2.97)$ & $<0.001$ \\
\hline Platelet $\left(10^{9} / \mathrm{L}\right)$ & $265.3 \pm 124.1$ & $268.8 \pm 109.7$ & $3.50(-7.04-14.04)$ & 0.515 \\
\hline Transfusions & $1.8 \pm 1.9$ & $1.5 \pm 1.7$ & $0.302(0.181-0.424)$ & $<0.001$ \\
\hline
\end{tabular}

be gestational age- and birth weight-dependent. In this subgroup of infants with a gestational age of $<28$ weeks, we only have 76 infants in the rhEPO treatment group and 71 in the control group, and infants with birth weight $<1000 \mathrm{~g}$, we only have 73 in the rhEPO treatment group and 74 in the control group. Considering the small number of ROP, the results from the current study for this group of infants is not conclusive. Indeed, in the most recently closed Preterm Erythropoietin Neuroprotection Trial (PENUT) for assessing the safety and efficacy of early high-dose erythropoietin for neuroprotection in extremely preterm infants, they found that in contrast to previous meta-analyses, treatment with rhEPO did not result in a higher rate or greater severity of retinopathy of prematurity than placebo [32].

In the subgroup analysis, rhEPO led to a decrease in the rate of type 2 ROP in infant boys but not in infant girls, suggesting a sex-differential response to rhEPO. It has been reported that the overall production of EPO is suppressed by oestrogen in rodents under normoxic or hypoxic conditions [33]. This finding suggests that sex hormones may modulate the non-haematopoietic EPO response. This also raises the possibility that EPO in infant boys is protective against ROP, whereas, in infant girls [34], against oestrogen-regulated EPO production in the reproductive organs [33]. This is consistent with findings from our study, which suggests that the benefit of EPO treatment on ROP is evident in infant boys but not in infant girls. Studies of the interaction between oestrogen and EPO signalling may further elucidate the direct and indirect contributions of oestrogen to sex-specific responses during EPO treatment, particularly in nonhaematopoietic tissues [35].

Anaemia of prematurity is a common condition in preterm infants, particularly in extremely preterm infants, born before 28 weeks of gestation [6, 36]. Early rhEPO treatment reduces the numbers of red blood cell transfusions in low birth weight infants [37]. However, it is unclear whether rhEPO treatment is a risk factor for ROP [6]. In our subgroup analysis, there was a non-significant increase in the incidence of type 2 ROP in infants with a gestational age of $<28$ weeks as well as in the incidence of type 1 ROP in infants with a birth weight of $<1000 \mathrm{~g}$, following early rhEPO treatment. This indicates that there may be a gestational age- and birth weight-dependent effect of rhEPO on ROP. Anaemia during the first postnatal week remained an independent significant risk factor for ROP requiring treatment. Reducing early anaemia in preterm infants may reduce their risk of developing ROP $[6,38]$. 
There were some limitations to the current study. First, EPO concentration was not measured longitudinally, even though this had been performed in our first rhEPO clinical studies (during which rhEPO was administrated to term infants with hypoxic ischemic encephalopathy) [39]. Therefore, we cannot establish the relationship between true EPO concentration and the rate of ROP in the current study to provide further information on the relationship between EPO serum concentration and ROP. Second, there were more male than female infants in the current study, which was a similar imbalance in sex ratio reported in other clinical studies with Chinese populations $[40,41]$. In addition, this study was only hospitals of Zhengzhou University, indicating that the sample size was not large enough, especially for the infant groups that had a gestational age of $<28$ weeks and a birth weight of $<1000 \mathrm{~g}$. Therefore, results obtained in these infant groups need to be interpreted with caution, especially because these two groups of preterm infants showed a statistically non-significant increase in the incidence of ROP following rhEPO administration. Lastly, the data presented is retrieved from preterm infants enrolled in our previous clinical trials that none of them was originally designed for evaluation of the effect of rhEPO for ROP. Hence, a more appropriately designed, list ROP as a primary outcome, multi-centre studies with a larger sample are needed to further explore the impact of the administration of rhEPO on the incidence of ROP in very preterm infants.

\section{Conclusions}

The observational analysis retrieved from our previous prospective randomised clinical trial data found that early repeated low-dose administration of rhEPO is safe for very preterm infants and reduced the need for red blood cell transfusions, but no significant effect on the overall incidence of ROP, even though the gestation age- and birth weight-dependent effect of rhEPO administration on ROP in preterm infants has been noticed. However, considering the overall relatively low incidence of ROP among preterm infants, data from more largescale clinical studies are needed to derive more conclusive results regarding rhEPO administration in very preterm infants.

\section{Abbreviations \\ ROP: Retinopathy of prematurity; rhEPO: Recombinant human erythropoietin; NICU: Neonatal intensive care units; PMA: Postmenstrual age; BPD: Bron- chopulmonary dysplasia; NEC: Necrotizing enterocolitis; IVH: Intraventricular hemorrhage.}

\section{Acknowledgements}

This study was supported by the National Key Research and Development Program of China (2018YFC1004604), the Department of Health and Family Planning Commission of Henan Province (201403260), and the Department of Science and Technology of Henan Province of China (134200510023, 171100310200). We thank all the pediatric ophthalmologists from two hospitals for the routine ROP screening and diagnosis, and Dr. Hui Yan, from the Research Center of the Children's Hospital affiliated to Zhengzhou University, for assistance with statistical analyses.

\section{Authors' contributions}

Conceptualization: CZ, HS, JS. Data curation: JS, WK, YW, XS, CZ, HX, FX, ML, XZ, $Z Y, X P, B L, Y X, S X$. Formal analysis: HS, JS. Funding acquisition: $C Z, H S$. Investigation: HS, JS. Methodology: CZ, XW, HS, JS. Project administration: HS, JS, WK, FX, ML, ZY, SX. Supervision: CZ. Validation: HS, JS. Visualization: WK, YW, CZ, HX, $X S, X Z, Z Y, X P, B L, Y X, S X$. Writing-original draft: HS. Writing-review \& editing: CZ, $X W$, JS. All authors read and approved the final manuscript.

\section{Funding}

Open access funding provided by University of Gothenburg.

\section{Availability of data and materials}

The datasets used and/or analyzed during the current study are included in this published article.

\section{Ethics approval and consent to participate}

This study protocol was approved by the Ethics Committee of Zhengzhou University and Henan Medical Academy (201201002).

\section{Consent for publication}

Not applicable.

\section{Competing interests}

We declare no competing interests.

\begin{abstract}
Author details
1 Department of Neonatology, Children's Hospital Affiliated to Zhengzhou University, Henan Children's Hospital, Zhengzhou Children's Hospital, Zhengzhou, China. ${ }^{2}$ Henan Key Laboratory of Child Brain Injury, Institute of Neuroscience and Third Affiliated Hospital, Zhengzhou University, Zhengzhou 450052, China. ${ }^{3}$ Department of Ophthalmology, Children's Hospital Affiliated to Zhengzhou University, Henan Children's Hospital, Zhengzhou, China. ${ }^{4}$ Key Laboratories of Children's Genetic Metabolic Diseases, Henan Province, Children's Hospital Affiliated to Zhengzhou University, Henan Children's Hospital, Zhengzhou, China. ${ }^{5}$ Centre of Perinatal Medicine and Health, Institute of Neuroscience and Physiology, University of Gothenburg, Gothenburg, Sweden. ${ }^{6}$ Center for Brain Repair and Rehabilitation, Institute of Neuroscience and Physiology, University of Gothenburg, Gothenburg, Sweden. ${ }^{7}$ Department of Women's and Children's Health, Karolinska Institutet, Stockholm, Sweden.
\end{abstract}

Received: 25 July 2020 Accepted: 3 October 2020

Published online: 19 October 2020

\section{References}

1. Ohlsson A, Aher SM. Early erythropoiesis-stimulating agents in preterm or low birth weight infants. Cochrane Database Syst Rev. 2017;11:cd004863.

2. den Besten G, van der Weide K, Schuerman F, Michael Cotten C, Rondeel $J M M$. Establishing the cause of anemia in a premature newborn infant. Lab Med. 2018;49(3):e74-e7777.

3. Ibonia KT, Bada HS, Westgate PM, Gomez-Pomar E, Bhandary P, Patwardhan $\mathrm{A}$, et al. Blood transfusions in preterm infants: changes on perfusion index and intermittent hypoxemia. Transfusion. 2018;58(11):2538-44.

4. Lopriore E. Updates in red blood cell and platelet transfusions in preterm neonates. Am J Perinatol. 2019;36(S02):S37-S40.

5. Banerjee J, Asamoah FK, Singhvi D, Kwan AW, Morris JK, Aladangady N. Haemoglobin level at birth is associated with short term outcomes and mortality in preterm infants. BMC Medi. 2015;13:16.

6. Lundgren P, Hellgren G, Pivodic A, Savman K, Smith LEH, Hellstrom A. Erythropoietin serum levels, versus anaemia as risk factors for severe retinopathy of prematurity. Pediatric Res. 2019;86(2):276-82.

7. Lundgren P, Athikarisamy SE, Patole S, Lam GC, Smith LE, Simmer K. Duration of anaemia during the first week of life is an independent risk factor for retinopathy of prematurity. Acta Paediatr. 2018;107(5):759-66. 
8. Aher SM, Ohlsson A. Late erythropoiesis-stimulating agents to prevent red blood cell transfusion in preterm or low birth weight infants. Cochrane Database Syst Rev. 2019;2:cd004868.

9. Song J, Sun H, Xu F, Kang W, Gao L, Guo J, et al. Recombinant human erythropoietin improves neurological outcomes in very preterm infants. Ann Neurol. 2016;80(1):24-34.

10. Hellstrom A, Smith LE, Dammann O. Retinopathy of prematurity. Lancet. 2013;382(9902):1445-577.

11. Dogra MR, Katoch D, Dogra M. An Update on Retinopathy of Prematurity (ROP). Indian J Pediatr. 2017;84(12):930-6.

12. Chen J, Connor KM, Aderman CM, Smith LE. Erythropoietin deficiency decreases vascular stability in mice. J Clin Invest. 2008;118(2):526-33.

13. Mowat FM, Gonzalez F, Luhmann UF, Lange CA, Duran Y, Smith AJ, et al. Endogenous erythropoietin protects neuroretinal function in ischemic retinopathy. Am J Pathol. 2012;180(4):1726-39.

14. Sato T, Kusaka S, Shimojo H, Fujikado T. Vitreous levels of erythropoietin and vascular endothelial growth factor in eyes with retinopathy of prematurity. Ophthalmology. 2009;116(9):1599-603.

15. Holm M, Skranes J, Dammann O, Fichorova RN, Allred EN, Leviton A. Systemic endogenous erythropoietin and associated disorders in extremely preterm newborns. Arch Dis Child Fetal Neonatal Ed. 2016;101(5):F458-F463463.

16. Holm M, Morken TS, Fichorova RN, VanderVeen DK, Allred EN, Dammann $\mathrm{O}$, et al. Systemic inflammation-associated proteins and retinopathy of prematurity in infants born before the 28th week of gestation. Invest Ophthalmol Vis Sci. 2017;58(14):6419-28.

17. Yang $X, Z$ e $B$, Dai $Y$, Zhu L, Chen $C$. The alteration and significance of erythropoietin serum levels in preterm infants with retinopathy of prematurity. Am J Perinatol. 2017;34(10):1020-5.

18. Suk KK, Dunbar JA, Liu A, Daher NS, Leng CK, Leng JK, et al. Human recombinant erythropoietin and the incidence of retinopathy of prematurity: a multiple regression model. J AAPOS. 2008;12(3):233-8.

19. Shah N, Jadav P, Jean-Baptiste D, Weedon J, Cohen LM, Kim MR. The effect of recombinant human erythropoietin on the development of retinopathy of prematurity. Am J Perinatol. 2010;27(1):67-71.

20. Chou HH, Chung MY, Zhou XG, Lin HC. Early erythropoietin administration does not increase the risk of retinopathy in preterm infants. Pediatr Neonatol. 2017;58(1):48-56.

21. Juul SE, Comstock BA, Wadhawan R, Mayock DE, Courtney SE, Robinson T, et al. A randomized trial of erythropoietin for neuroprotection in preterm infants. N Engl J Med. 2020;382(3):233-43.

22. Wang Y, Song J, Sun H, Xu F, Li K, Nie C, et al. Erythropoietin prevents necrotizing enterocolitis in very preterm infants: a randomized controlled trial. J Transl Med. 2020;18(1):308.

23. Chen Y, Feng J, Li F, Yin H, Liang J, Li X. Analysis of changes in characteristics of severe retionopathy of prematurity patients after screening guidelines were issued in China. Retina. 2015;35(8):1674-9.

24. Mitsiakos G, Papageorgiou A. Incidence and factors predisposing to retinopathy of prematurity in inborn infants less than 32 weeks of gestation. Hippokratia. 2016;20(2):121-6.

25. Heeger LE, Counsilman CE, Bekker V, Bergman KA, Zwaginga JJ, Te Pas $A B$, et al. Restrictive guideline for red blood cell transfusions in preterm neonates: effect of a protocol change. Vox Sang. 2019;114(1):57-62.
26. Fierson WM. Screening examination of premature infants for retinopathy of prematurity. Pediatrics. 2018;142(6):e20183061.

27. International Committee for the Classification of Retinopathy of Prematurity. The International Classification of Retinopathy of Prematurity revisited. Arch Ophthalmol. 2005; 123(7):991-9.

28. Singer M, Deutschman CS, Seymour CW, Shankar-Hari M, Annane D, Bauer $\mathrm{M}$, et al. The third international consensus definitions for sepsis and septic shock (Sepsis-3). JAMA. 2016;315(8):801-10.

29. Higgins RD, Jobe AH, Koso-Thomas M, Bancalari E, Viscardi RM, Hartert TV, et al. Bronchopulmonary dysplasia: executive summary of a workshop. J Pediatr. 2018;197:300-8.

30. Battersby C, Santhalingam T, Costeloe K, Modi N. Incidence of neonatal necrotising enterocolitis in high-income countries: a systematic review. Arch Dis Child Fetal Neonatal Ed. 2018;103(2):F182-F189189.

31. Calisici E, Eras Z, Oncel MY, Oguz SS, Gokce IK, Dilmen U. Neurodevelopmental outcomes of premature infants with severe intraventricular hemorrhage. J Materm Fetal Neonatal Med. 2015;28(17):2115-200.

32. Ohlsson A, Aher SM. Early erythropoiesis-stimulating agents in preterm or low birth weight infants. Cochrane Database Syst Rev. 2020;2:Cd004863.

33. Zhang $Y$, Rogers HM, Zhang $X$, Noguchi $C T$. Sex difference in mouse metabolic response to erythropoietin. FASEB J. 2017;31(6):2661-733.

34. Lavoie JC, Tremblay A. Sex-specificity of oxidative stress in newborns leading to a personalized antioxidant nutritive strategy. Antioxidants. 2018;7(4):49.

35. Li X, Liu CX, Xue W, Zhang Y, Jiang S, Yin QF, et al. Coordinated circRNA biogenesis and function with NF90/NF110 in viral infection. Mol Cell. 2017;67(2):214-27.e7

36. Jopling J, Henry E, Wiedmeier SE, Christensen RD. Reference ranges for hematocrit and blood hemoglobin concentration during the neonatal period: data from a multihospital health care system. Pediatrics. 2009;123(2):e333-e337.

37. Ohlsson A, Aher SM. Early erythropoietin for preventing red blood cell transfusion in preterm and/or low birth weight infants. Cochrane Database Syst Rev. 2014;4:cd004863.

38. Rocha G, Pereira S, Antunes-Sarmento J, Flor-de-Lima F, Soares H, Guimaraes H. Early anemia and neonatal morbidity in extremely low birth-weight preterm infants. J Matern Fetal Neonatal Med. 2019. https:// doi.org/10.1080/14767058.2019.1689948.

39. Zhu C, Kang W, Xu F, Cheng X, Zhang Z, Jia L, et al. Erythropoietin improved neurologic outcomes in newborns with hypoxic-ischemic encephalopathy. Pediatrics. 2009;124(2):e218-e226226.

40. Wang H, Gao X, Liu C, Yan C, Lin X, Yang C, et al. Morbidity and mortality of neonatal respiratory failure in China: surfactant treatment in very immature infants. Pediatrics. 2012;129(3):e731-e740740.

41. Sun H, Cheng R, Wang Z. Eearly vitamin A supplementation improves the outcome of retinopathy of prematurity in extremely preterm infants. Retina. 2020;40(6):1176-84.

\section{Publisher's Note}

Springer Nature remains neutral with regard to jurisdictional claims in published maps and institutional affiliations.

Ready to submit your research? Choose BMC and benefit from

- fast, convenient online submission

- thorough peer review by experienced researchers in your field

- rapid publication on acceptance

- support for research data, including large and complex data types

- gold Open Access which fosters wider collaboration and increased citations

- maximum visibility for your research: over 100M website views per year

At BMC, research is always in progress.

Learn more biomedcentral.com/submissions 